\title{
EPIDEMIOLOGICAL AND IMMUNOLOGICAL SURVEYS IN NETHERLANDS NEW GUINEA
}

\author{
D. L. LEIKER, M.D. \\ formerly Chief of Division of Leprosy Control, \\ Netherlands New Guinea
}

\section{Epidemiology}

SLOAN AND LEIKER' carried out the first systematic surveys in 1952 in Netherlands New Guinea, and even at that early stage noted marked differences in prevalence and type rate in the different parts of the country, and also strong evidence of the recent introduction of leprosy in several areas. After 1952 Leiker extended and intensified these systematic surveys, and was helped by the collection of valuable data by some district government medical officers. At the end of five years he could draw a fairly accurate picture of the leprosy situation.

In some areas it has been possible to trace the course of the endemia from its first introduction, and representative areas were studied in detail and revealed a strikingly different pattern. In the method of survey an accurate record was first made of the inhabitants of every house in the village, and then medical examination made of the total population. This procedure was repeated annually, care being taken to examine inhabitants in temporary residence elsewhere. An almost complete survey was thereby attained in a few years. Much effort was put into education about leprosy during and between the surveys, and this generated increasing interest in the disease, very good cooperation from the people, and much voluntary giving of information. The oldest inhabitants in areas where the disease was well known gave valuable information. They were asked about lepromatous patients who had died before the survey was made. No enquiry was made about tuberculoid patients, because there is a good chance of confusing this leprosy with crippling forms of yaws, and similar diseases. Because in many areas leprosy is a recent disease there were still old people living who had known intimately the first lepromatous patient in the village. Verification of the information was obtained from informants in other villages. Genealogical tables were prepared for all deceased and living patients, and extensive data obtained about the origins of families, clans, and villages, and other inter-relationships. Verification of data could be obtained by referring to events which were of local importance, e.g., the arrival of the first missionary, the opening of the first school, the presence of a well known teacher or government official. There is strong evidence that leprosy was introduced 
between 1800 and 1805, into some villages of the Radja Ampat Island group, in the west of New Guinea. Between 1850 and 1900 the Biak and Numfor people were infected; they had previously migrated to these islands. Leprosy did not spread from these islands until about 1870 when Numfor people brought it from these islands to Manokwari where they settled at the centre of the north coast of the mainland. The Dutch missionary, van Hasselt, in 1879 stated that the number of leprosy patients at Manokwari was increasing, which is the first written mention of leprosy. The missionaries lived in the village and knew every inhabitant and often treated their diseases and the fact that their early reports seldom mentioned leprosy supports the idea that the disease is of recent introduction in most parts of New Guinea.

The first patient in Wandamen Bay was seen about the year 1903. The son of this patient was alive at the time of the first survey and confirmed this information. Since then leprosy has spread over the interior area, and the history of this spread can be traced almost completely. In 1957 the last survey found an incidence of 80 per thousand. Further spread of leprosy along the coast of New Guinea has taken place in this century, and the spread of leprosy to the interior has been discovered in the past 30 years. This is a serious matter. A modern anti-leprosy campaign has been started in the coast area, with good hope of success within a reasonable time, but the inland situation is unfavourable and difficult.

This recent inland spread of leprosy follows from increase in the amount of contact between the more sophisticated coastal people and the backward tribes of the interior. Contact was previously limited to incidental trade, warfare, and slave hunting. Personal contact and house contact were exceptional. In the present era after pacification inland people show a growing tendency to move to the coast and set up an increasing number of villages at the coast. Even though coastal people still feel superior to the bush people there is a considerable amount of intimate contact and even intermarriage has occurred. Knowledge of the history and customs of the peoples is of utmost importance for understanding the variable patterns of disease in New Guinea. This paper will deal with some representative coastal and inland peoples who now live in the same area.

West New Guinea in the coastal part was ruled for many centuries by the Indonesian sultans of Ternate and Tidore under four radjas who were settled on some islands of the Radja Ampat Island group ("four kings"). Indonesian and part-Indonesian descendants are still living in some of these villages. These so-called "Maja" groups are considered to represent the oldest leprosy foci in New Guinea. About 400 years ago several groups of Biak and Numfor peoples migrated from their islands which lie north of Geelvinck Bay and the sultans allowed them to settle on some islands of the Radja Ampat 
group. They were sea-going people and they stayed at the coast, and the local population of the islands dwelt in the interior.

Numfor people settled on the small islands of Doom, Jefinan, and Arar, and the Biak people (also called the "Beser") settled at South Waigeo and many adjacent islands. The Numfor and Biak peoples comprised the second group to be infected with leprosy. Later Biak groups settled on the east and north coast of Waigeo and in a few villages on the north coast of the mainland. These groups are also called Usba, Wardo, and Sopen, and were infected in New Guinea. The Amber group inhabited the central area of Waigeo, being the first inland tribe to move to the coast and also the first of the island residents to contract leprosy. A similar situation is found at Salawati Island and on the north coast of the mainland.

As shown by maps of the close of last century there are very few villages on the north coast of west New Guinea. These are small settlements of Maja and Beser, or temporary camps of inland people for incidental trading. The movement to the coast increased greatly between 1900 and 1930 and the maps show many names of permanent or semi-permanent small villages of inland people. The Mooi tribe of the outer west part of the mainland and partly at Salawati Island moved to the coast and became the first tribe in the area to be infected with leprosy. Most of the villages were only infected after 1925, and some only very recently, The Madik, Morait, and Karoon tribes, living in the interior more to the east, were infected late, and many of their villages are still free of leprosy.

Between 1952 and 1957 repeated surveys were carried out in these areas and Table 1 gives the situation at the end of 1957.

\section{TABLE 1}

Prevalence and Type Index in Coastal and Interior People in West New Guinea

\begin{tabular}{l|c|c|c|c|c}
\hline \multicolumn{1}{c|}{ Group } & Population & $\begin{array}{c}\text { Number } \\
\text { of } \\
\text { Cases }\end{array}$ & Prevalence & $\begin{array}{c}\text { Lepro- } \\
\text { matous } \\
\text { Cases }\end{array}$ & $\begin{array}{c}\text { Type } \\
\text { Index }\end{array}$ \\
\hline Maja & 500 & 27 & $5.4 \%$ & 11 & 41 \\
\hline $\begin{array}{l}\text { Beser } \\
\text { Numfor }\end{array}$ & 3,200 & 129 & $4 \%$ & 44 & 34 \\
\hline $\begin{array}{l}\text { Usba } \\
\text { Wardo } \\
\text { Sopen }\end{array}$ & 3,000 & 143 & $4.8 \%$ & 28 & 20 \\
$\begin{array}{l}\text { Mooi } \\
\text { Morait } \\
\text { Madik }\end{array}$ & 5,000 & 403 & $8 \%$ & 48 & 12 \\
\hline
\end{tabular}

It may be concluded:

1. that leprosy has spread very fast in the recently infected areas: on several occasions a higher incidence was found compared with coastal areas with a history of the disease twice as long; 2. there was a constant finding of a low type index; tuberculoid cases predominated, often with only one or a few macules; 3 . the tuberculoid patients are distributed over many houses, and as a rule lepromatous cases were few or absent; 4. though leprosy is of 
recent introduction, the number of adult patients is relatively high, and there is no doubt that a high proportion of the patients sustained infection long after childhood.

Herein is a striking contrast to the pattern of leprosy in most coastal tribes. The usual ideas about leprosy seem to hold true for the coast, namely that it is a disease only mildly contagious, that adults are less susceptible, that prolonged intimate contact, in family or house usually, is needed to produce transmission of the disease, with "leprosy families", "leprosy foci", and "leprosy villages" as a regular part of the picture. There is also moderate or even slow increase of the leprosy incidence, and decades pass without attaining an even distribution of the cases, and the type incidence is much higher and children are much more susceptible than adults.

In the Ransiki area on the west coast of Geelvinck Bay a similar development took place. Coastal people from Windesi inhabited Rumberpon Island. About 1925, leprosy was introduced into two of the four Windesi villages, and the leprosy index in the other two villages is still very low.

The nearby mainland was inhabited in this century by the Manikion tribe, but most of the tribe still live in the interior. Rarely intermarriage occurs between the Windesi and Manikion. The first infection of Manikion coastal villages took place in the last two decades. Further over to the interior most villages are still free of leprosy. The present situation is given in Table 2 .

\section{TABLE 2}

Prevalence and Type Index Rumberpon Area

\begin{tabular}{l|c|c|c|c|c}
\hline \multicolumn{1}{c|}{ Group } & Population & $\begin{array}{c}\text { Number } \\
\text { of } \\
\text { Cases }\end{array}$ & $\begin{array}{c}\text { Leprosy } \\
\text { Index }\end{array}$ & $\begin{array}{c}\text { Lepro } \\
\text { matous } \\
\text { Cases }\end{array}$ & $\begin{array}{c}\text { Type } \\
\text { Index }\end{array}$ \\
\hline $\begin{array}{l}\text { Windesi } \\
\text { (Rumberpon) }\end{array}$ & 430 & 38 & $8.8 \%$ & 13 & $33 \%$ \\
\hline Manikion & 950 & 49 & $5.2 \%$ & 4 & $8 \%$ \\
\hline
\end{tabular}

Here also the recently infected Manikion villages show a high prevalence, a low type index, distribution of patients over many houses in the village, and a relative preponderance of adult patients. Leprosy is spreading rapidly to the interior and follows the same pattern as described above.

In Kaimana the disease has followed the usual coastal pattern after some coastal villages were infected about 1920 . On the mainland lives the inland tribe, the Mairasi, of whom a small group settled at the coast in this century at Lobo. A second group lives inland about one day's walking distance from Lobo. The first leprosy case appeared 
at Lobo between 1930 and 1940. Further spread to the interior was noted during the war. The situation is given in Table 3 .

TABLE 3

Prevalence and Type Index Kaimana

\begin{tabular}{l|c|c|c|c|c}
\hline \multicolumn{1}{c|}{ Group } & Population & $\begin{array}{c}\text { Number } \\
\text { of } \\
\text { Cases }\end{array}$ & $\begin{array}{c}\text { Leprosy } \\
\text { Index }\end{array}$ & $\begin{array}{c}\text { Lepro- } \\
\text { matous } \\
\text { Cases }\end{array}$ & $\begin{array}{c}\text { Type } \\
\text { Index }\end{array}$ \\
\hline $\begin{array}{l}\text { Coastal } \\
\text { groups }\end{array}$ & 1,815 & 83 & $4.6 \%$ & 19 & $23 \%$ \\
\hline Maidasi & 324 & 36 & $11 \%$ & 2 & $6 \%$ \\
\hline
\end{tabular}

Once more we see that the leprosy index is high among the mountain people after only a short history of the disease, with again a low type index. This situation has been found to be repeated in other parts of Netherlands New Guinea.

The coastal pattern of leprosy in New Guinea is much the same as in many other countries and gives findings which correspond, namely:

1. the disease spreads slowly after introduction; 2. foci persist in the endemic area even after a long history, and there are families and villages with a significantly higher leprosy index than others in the area; 3. the type index is variable, but seldom lower than 20 to $25 \%$, and often higher; 4. a relatively high proportion of cases is found among children and young adults; 5 . contact with lepromatous leprosy is evident in a high percentage of the new cases: this contact is very often prolonged intimate house contact, and often family contact.

Among people who have lived in relative isolation until recently' the pattern is very different, namely:

1. the disease spreads fast after its introduction; 2. cases are distributed over many houses, and foci seem to be of minor importance; 3. the type index is very low, so that there is almost an epidemic of tuberculoid leprosy, and cases predominate which have only one or a few tuberculoid macules; 4. adults are almost as susceptible as children; 5. cases giving a history of contact with lepromatous patients are the minority, and even in these there has not been prolonged intimate house contact.

This epidemiology recalls the Nauru epidemic, the early leprosy history of New Caledonia, and the recent history of some parts of West and Central Africa. There are many areas with a situation intermediate between the two extremes. It is possible that the same factors operate in many countries.

A detailed study has been made of some of the areas in Nether- 
lands New Guinea in order to gain more insight into the factors concerned.

\section{Mantemhu}

There are two main groups in the population of Japen Island, north of Geelvinck Bay. The first group of basically coastal people, occupying villages with 500-3,000 inhabitants, has lived for many centuries at the coast. There has been some contact with the outside world for a long time. Leprosy was introduced in a few villages about 30 years ago, and in other villages even later. Af ter these 30 years the leprosy index has not passed 3\%, the type index varies between 25 and $35 \%$, and the pattern of leprosy is of the coastal type, described above.

The second population group consists of inland people who moved to the coast $25-35$ years ago. Only a few villages are left in the mountains, and a few can be found near the coast, but the majority are on the coast. These villages are usually small and the number of inhabitants does not exceed 300 . The people are not yet completely adapted to life at sea, the protein intake is low, the birth rate is low, and the death rate is higher than among primary coastal people.

Leprosy was introduced in the secondary coastal villages only very recently. Several villages are still leprosy free. The village of Mantembu with 340 inhabitants was the object of a detailed study. The population moved from the mountains about 1926 and settled three miles from the coast. The first cases of leprosy appeared during the war. Thereafter the disease has spread very rapidly. After 15 years it was found that $15 \%$ of the population showed symptoms of leprosy. The first leprosy survey was held in 1952 by Sloan and Leiker. Although $80 \%$ of the population was examined and a leprosy index of 80 per thousand was found, not a single lepromatous patient was seen. The author has repeated this survey in 1954 and in 1957. The whole population was examined and the leprosy index rose to 150 per thousand. The first "infectious" patient was seen in 1954; in 1952 this patient showed a few indeterminate macules. He stated that these macules had appeared first in 1946. Smears of these macules were negative on routine examination in 1952. In 1954 the patient was classified as borderline and lesions showed $2+$ smears with few globi. The people in the village denied strongly that there had ever been a lepromatous case in the village before 1954 .

People show no leprosy fear, they never avoid an examination, and have always cooperated excellently. Af ter several years of almost daily contact with these people, I am convinced that their statement is justified. They know the clinical symptoms of lepromatous leprosy quite well since a small leprosy village existed in the neighbourhood between 1934 and 1935. Also a woman from Mantembu was married in another village at the coast and her husband had lepromatous leprosy before the war. The development of the leprosy endemic is shown in Table 4. 
TABLE 4

Onset of New Cases of Leprosy at Mantembu

\begin{tabular}{lccc}
\hline Period & T. cases & B. cases & Total \\
\hline $1944-46$ & 4 & - & 4 \\
\hline $1947-49$ & 7 & - & 7 \\
\hline $1950-52$ & 12 & - & 12 \\
\hline $1953-55$ & 15 & 3 & 18 \\
\hline 1956 & 1 & 1 & 2 \\
\hline dubious & 9 & - & 9 \\
\hline
\end{tabular}

After an initial slow increase in the number of new cases, a sudden explosion of new tuberculoid cases followed and thereafter, before any effective protective measures were taken, a decrease in the number of new cases was seen.

In Table 5 it is seen that not long after introduction of leprosy, patients were found in $28^{\circ}$ of the 39 houses in the village. Although two houses showed a particularly high prevalence, such a distribution of cases is very unusual in coastal villages, even after a much longer history. Leprosy was distributed about evenly among the sexes at Mantembu.

TABLE 5

Distribution of Leprosy at Mantembu

\begin{tabular}{c|c|c}
\hline $\begin{array}{c}\text { Number of } \\
\text { Cases } \\
\text { per House }\end{array}$ & $\begin{array}{c}\text { Number of } \\
\text { Houses }\end{array}$ & $\begin{array}{c}\text { Total } \\
\text { Patients }\end{array}$ \\
\hline 0 & 11 & 0 \\
1 & 15 & 15 \\
2 & 9 & 18 \\
3 & 2 & 6 \\
4 & 1 & 4 \\
5 & 1 & 5 \\
moved & & 3 \\
\hline Total & & 51 \\
\hline
\end{tabular}

In coastal areas as a rule the prevalence of tuberculoid leprosy is much higher among females than among males; not seldom a 2:1 
rate is found. The prevalence of leprosy in children is low at Mantembu. The child index is $8 \%$. In coastal villages an index of $15-20 \%$ is usually found. A type index of $8 \%$ is very low, compared with coastal villages which usually show indices between 20 and $35 \%$.

In Table 6 the attack rate per age group is shown.

TABLE 6

Age at Onset of Symptoms and Attack Rate per Age Group at Mantembu

\begin{tabular}{l|c|c|c|c|c|c}
\hline Age Group & $0-4$ & $5-9$ & $10-14$ & $15-19$ & $20-39$ & $\begin{array}{l}40+ \\
\text { Years }\end{array}$ \\
\hline Population & 68 & 34 & 30 & 33 & 110 & 69 \\
\hline $\begin{array}{l}\text { Distribution of Patients } \\
\text { According to Age at }\end{array}$ & 0 & 5 & 7 & 13 & 18 & 7 \\
Onset of First Symptoms & $0 \%$ & $10 \%$ & $14 \%$ & $26 \%$ & $36 \%$ & $14 \%$ \\
\hline Incidence per Age Group & $0 \%$ & $15 \%$ & $23 \%$ & $39 \%$ & $16 \%$ & $10 \%$ \\
\hline
\end{tabular}

If we assume that the age distribution at Mantembu has not changed essentially during the past 20 years and if we assume that the incubation period of leprosy is in the majority of cases not much longer than 5 years, an important percentage of the patients at Mantembu must have been infected after childhood and several patients even at an advanced age. Two sources of infection have to be considered as a possibility. There is firstly the small leprosy village which existed in the neighbourhood between 1934 and 1935. However, the interval between the closing of the leprosarium and the manifestation of symptoms in the first patient at Mantembu is 9 years, and the majority of the cases appeared much later still. Such a long incubation period is exceptional and improbable for the majority of the cases. Besides, intimate contact with the patients was denied, which is easy to understand since the patients in the leprosarium were coastal people who came from a distant area and suffered from an unknown and serious disease. The second source of infection is more important. The fact that a woman of the clan Ambokari was married to a lepromatous man at the village Tarau implied that members of the Ambokari family also visited the house at Tarau and not infrequently spent the night there. To evaluate this source of infection genealogical tables were prepared from all patients. It was learned that $35 \%$ of the patients were in one way or another related to the Ambokari family. The two houses with the highest leprosy index were related to the Ambokari family. Although one may assume that several patients were infected by the patient at 


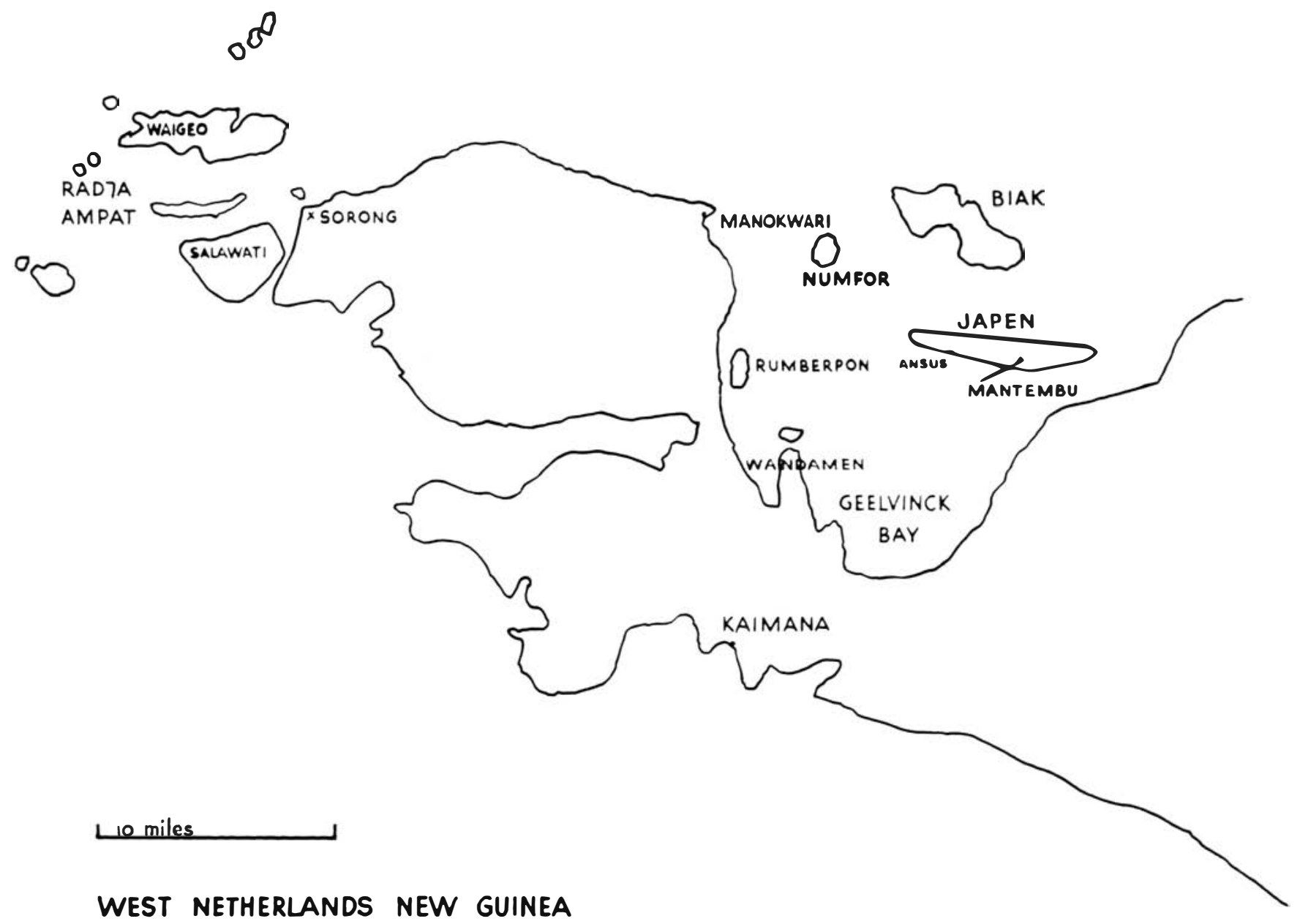


TABLE 7

Reactions to P.P.D. 5 TU in different age groups

$\frac{\%}{40}$

30 .

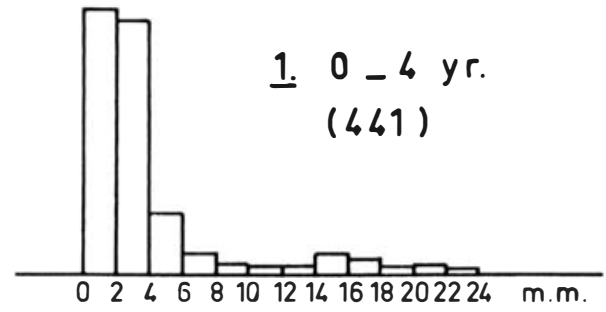

$\%$

2. $5-9$ yr.

20.

( 267 )

10.

0 .

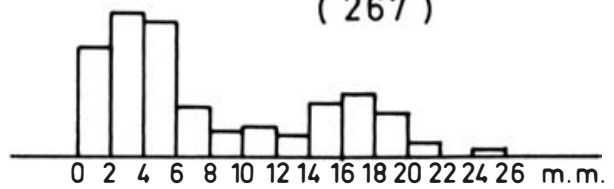

$\frac{\%}{20}$

3. $10-14$ yr.

(247)

10.

0.

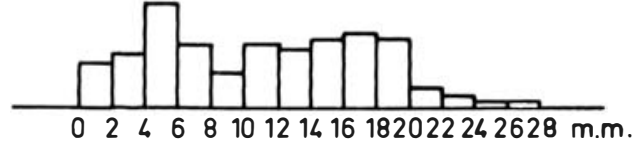

$\%$

4. 15 - 19 уг.

20 .

(180)

10.

0.

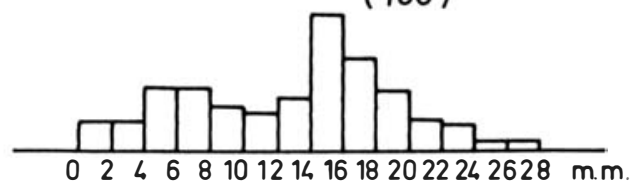

$\frac{\%}{20}$

5. 20-39 уг.

10.

0 .

$\frac{\%}{20}$

6. $40+y r$.

10.

0 .

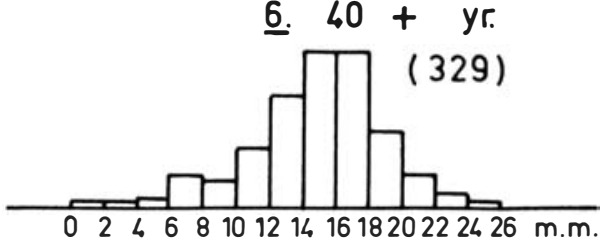


Tarau, there is no doubt that of the $35 \%$ of the patients who were related to this family the relationship was such a distant one that they had no intimate contact. Of the remaining $65 \%$ only a few may have had incidental superficial contact with the Tarau patient: it is certain that the majority did not have any contact at all. It is impossible to explain the epidemic at Mantembu by contact with lepromatous patients alone.

It is quite unlikely that the borderline patient discovered in 1954 has been strongly positive for such a long time. In 1952 routine smears were negative and even if repeated smears might have been positive, certainly this case was not a highly contagious one; also no further evidence could be detected that other patients were infected by this case.

The only possibility that remains is that tuberculoid leprosy has played a role in the dissemination of the disease. In our experience it is seldom necessary to assume that patients at the coast are infected by tuberculoid cases, although not always intimate and prolonged contact with lepromatous cases is evident in the majority of cases. At Mantembu, however, we have to accept the only possibility that some tuberculoid patients have acted as a source of infection. Especially the major tuberculoid and the reactional tuberculoid seem to be important. It is a well known fact that some of these cases may be rather strongly positive for some time, before becoming negative spontaneously. The survey showed that at Mantembu such cases were not rare. A history of red, raised, infiltrated lesions was obtained in several instances. After spontaneous regression, sometimes with ulceration, the asymmetrical, sharply defined, atrophic lesions were still visible at the time of the survey. It was not necessary to assume that minor tuberculoid lesions have played an important part in the dissemination of leprosy at Mantembu.

Since tuberculoid leprosy has played a part in the epidemiology in Mantembu, the population must be highly susceptible to leprosy. Factors such as climate offer no explanation. At Ansus, a coastal village with 3,000 inhabitants, on the same island, leprosy was introduced more than 25 years ago. The leprosy index is now only 10 per thousand; the type index is $35 \%$. The disease is limited to only a few clans and within these clans a few houses show a high prevalence of leprosy.

Race, hygiene, customs, offer no explanation. At Mariadei, a village near Mantembu, belonging to the same tribe, leprosy was introduced 12 years ago. The leprosy index is 47 per thousand, the type index is $27 \%$, the child index is $22 \%$.

Between Mantembu and other villages of inland tribes, recently settled at the coast, and the primary coastal settlements, we have found only one important difference, the degree of isolation as a 
community. We have considered the possibility that these relatively isolated groups have also remained free from tuberculosis until recently. This hypothesis is supported by the experience that although tuberculosis is a common disease along the coast we rarely found evidence of it in people living more inland. The people of Mantembu are frequent visitors at the hospital and polyclinic but we did not see a single case of tuberculosis during 4 years.

To verify this hypothesis tuberculin surveys were held at Mantembu, Mariadei, in Mooi people in West New Guinea, and also in coastal people from Wandamen Bay and West New Guinea.

\section{Immunology}

In many countries the injection of 5TU P.P.D. is followed by a very weak reaction, which does not exceed $5 \mathrm{~mm}$., and which is caused by needle trauma and buffer fluid, or by a larger reaction which is caused by previous contact with $M$. tuberculosis.

In many other countries, New Guinea included, there are other unknown factors, which produce non specific tuberculin reactions. Therefore it is not justifiable to apply criteria for positivity of the tuberculin test without preliminary research.

\section{TABLE 8}

Reactions to 5 TU Human P.P.D. (2gb)

\begin{tabular}{|c|c|c|c|c|c|c|c|}
\hline & 0 & 4 & 8 & 12 & 16 & 20 & $24 \mathrm{~mm}$ \\
\hline$+9 \mathrm{~mm}$. & 2 & 1 & 1 & & & & \\
\hline$+8 \mathrm{~mm}$ & 1 & 1 & & & & & \\
\hline$+7 \mathrm{~mm}$ & & & 1 & & & & \\
\hline$+6 \mathrm{~mm}$ & & 2 & 1 & 2 & 1 & & \\
\hline$+5 \mathrm{~mm}$ & 2 & 5 & 2 & 1 & & & \\
\hline$+4 \mathrm{~mm}$ & 5 & 4 & 3 & 2 & 1 & & \\
\hline$+3 \mathrm{~mm}$ & 13 & 5 & 4 & 4 & 1 & 2 & \\
\hline$+2 \mathrm{~mm}$ & 25 & 12 & 1 & 3 & 3 & & \\
\hline$+1 \mathrm{~mm}$ & 18 & 12 & 6 & 7 & 4 & 3 & \\
\hline $0 \mathrm{~mm}$ & 61 & 10 & 1 & 4 & 3 & & 1 \\
\hline$-1 \mathrm{~mm}$ & 3 & 2 & 2 & 2 & 4 & 1 & \\
\hline$-2 \mathrm{~mm}$ & & & 1 & 2 & 2 & 3 & \\
\hline$-3 \mathrm{~mm}$ & & & 2 & 3 & 1 & 1 & \\
\hline$-4 \mathrm{~mm}$. & 1 & & 1 & 2 & 1 & & 1 \\
\hline$-5 \mathrm{~mm}$ & & & & & 4 & 2 & \\
\hline$-6 \mathrm{~mm}$ & & & & & 1 & & 1 \\
\hline$-7 \mathrm{~mm}$ & & & & & & 3 & \\
\hline$-8 \mathrm{~mm}$. & & & & & & 4 & \\
\hline$-9 \mathrm{~mm}$. & & & & & 1 & 3 & 1 \\
\hline $\begin{array}{l}\text { Average } \\
\text { Difference }\end{array}$ & +1.2 & +2.2 & +2.0 & +0.9 & -1.0 & -4.1 & -5.0 \\
\hline
\end{tabular}




\section{TABLE 9}

Reactions to 5TU Human PPD in Different Peoples in Netherlands New Guinea

\begin{tabular}{|c|c|c|c|c|c|c|c|c|c|c|c|c|c|c|c|c|c|c|}
\hline & & & & \multicolumn{3}{|c|}{$M A N T E M B U$} & \multicolumn{3}{|c|}{$M A R I A D E I$} & \multicolumn{3}{|c|}{$W A N D A M E N$} & \multicolumn{3}{|c|}{ MOOI } & \multicolumn{3}{|c|}{ SORONG } \\
\hline $0-9$ & $\cdots$ & $\cdots$ & $\ldots$ & 91 & 5 & 5.5 & 122 & 8 & 6.6 & 708 & 104 & 14.7 & 137 & 4 & 2.9 & 395 & 57 & 14.4 \\
\hline $10-19$ & $\ldots$ & $\ldots$ & $\ldots$ & 42 & 10 & 23.9 & 58 & 23 & 39.8 & 427 & 219 & 51.2 & 115 & 22 & 19.1 & 347 & 115 & 33.1 \\
\hline \multicolumn{3}{|c|}{ Leprosy Index } & $\ldots$ & \multicolumn{3}{|c|}{$15 \%$} & \multicolumn{3}{|c|}{$4.5 \%$} & \multicolumn{3}{|c|}{$8.6 \%$} & \multicolumn{3}{|c|}{$10.1 \%$} & \multicolumn{3}{|c|}{$4.4 \%$} \\
\hline Type & Index & $\ldots$ & $\ldots$ & \multicolumn{3}{|c|}{$8 \%$} & \multicolumn{3}{|c|}{$28 \%$} & \multicolumn{3}{|c|}{$28 \%$} & \multicolumn{3}{|c|}{$12 \%$} & \multicolumn{3}{|c|}{$22 \%$} \\
\hline
\end{tabular}


TABLE 10

Reactions to 5TU Human PPD in a Manikion Group Living in the Interior

\begin{tabular}{|c|c|c|c|c|c|c|c|c|c|c|c|c|c|c|}
\hline Age Group & $0-4$ & $5-9$ & $10-14$ & $15-19$ & $20-39$ & $40+$ & Total & $0-4$ & $5-9$ & $10-14$ & $15-19$ & $20-39$ & $40+$ & Total \\
\hline Number tested & 35 & 25 & 14 & 10 & 39 & 22 & 145 & 30 & 22 & 7 & 10 & 59 & 10 & 138 \\
\hline $\begin{array}{l}10 \mathrm{~mm} . \\
\text { (negative) }\end{array}$ & 35 & 25 & 14 & 7 & 34 & 17 & 132 & 0 & 0 & 0 & 0 & 0 & 0 & 0 \\
\hline $\begin{array}{l}10-13 \mathrm{~mm} . \\
\text { (dubious) }\end{array}$ & 0 & 0 & 0 & 0 & 2 & 3 & 5 & 0 & 0 & 0 & 0 & 1 & 0 & 1 \\
\hline $\begin{array}{l}14 \mathrm{~mm} \text {. or more } \\
\text { (positive) }\end{array}$ & 0 & 0 & 0 & 3 & 3 & 2 & 8 & - & - & - & - & - & - & - \\
\hline
\end{tabular}


We can perceive from size frequency distribution histiograms of tuberculin reactions that the influence of non-specific factors increases with age. Only in young children specific and non-specific factors are more or less separated. In histiograms of adults it is impossible to distinguish between specific and non-specific reactions. From histiograms of young people we concluded that reactions smaller than $10 \mathrm{~mm}$. were caused by non-specific factors and reactions of $14 \mathrm{~mm}$. or larger by tuberculosis contact. Reactions between 10 and $14 \mathrm{~mm}$. are of doubtful origin.

Further evidence was obtained by injecting human and avian tuberculin simultaneously. This was suggested by WYSMULLER ${ }^{2}$ and based upon the hypothesis that in people infected with tuberculosis a homologous tuberculin would give stronger reactions than a heterologous tuberculin.

From Table 8 can be seen that in people with a reaction to human tuberculin larger than $14 \mathrm{~mm}$. the reaction to avian tuberculin is on the average smaller; whereas in people with a reaction to human tuberculin smaller than $14 \mathrm{~mm}$. the reaction to avian tuberculin is on the average larger. This was considered as support for the former findings that in the areas tested only reactions of $14 \mathrm{~mm}$. or larger are caused by $M$. tuberculosis.

Table 9 shows the percentages of positive tuberculin reactions in different age groups from some areas mentioned in this article. There is a difference between Mantembu and Mooi people and people from coastal areas. The tuberculin index in secondary coastal villages is much lower. The difference is in all age groups statistically highly significant $(\mathrm{P}<<0.001)$.

Table 10 shows the tuberculosis situation in a leprosy-free Manikion group still living in the mountains in the interior. The tuberculosis index is very low. Women and children have a negative tuberculin reaction. This can be explained by the fact that men more often go to the coast as carriers during patrols of officials and for trading purposes. Tuberculosis is a rare disease in the interior or it has been only recently introduced.

We have seen that the tuberculosis index is low in areas where leprosy manifests itself as an epidemic of macular tuberculoid leprosy. If our hypothesis is correct that previous tuberculosis contact reduces the chance of tuberculoid leprosy then we must also expect a lower tuberculin index in tuberculoid patients compared with healthy individuals from the same area and of the same age group, at least in young leprosy foci with a low tuberculosis index. In older foci with a high tuberculosis index the chance of finding significant differences is reduced since a large number of symptomfree tuberculoid patients may have had contact with $M$. tuberculosis after showing symptoms of tuberculoid leprosy, or even between infection with $M$. leprae and the manifestation of the first leprosy 
symptoms. The results of this. survey are given in Table 11.

In young leprosy foci with a rather low tuberculosis index tuberculoid patients do indeed show a lower tuberculin index than healthy people of the same area. This difference is less evident in older leprusy foci, such as Wandamen Bay, with a high tuberculosis index. The difference between the percentages of negative P.P.D. reactions in the total of tuberculoid patients and the healthy people is statistically significant. Also the difference in the Mooi people alone is statistically significant $(P<0.025)$.

TABLE 11

Tuberculin Index in Healthy Adults and Adult Tuberculoid Patients from the Same Area

\begin{tabular}{l|c|c|c||r|r|r}
\hline \multirow{2}{*}{} & \multicolumn{3}{|c||}{ Healthy Adults } & \multicolumn{3}{c}{ Tuberculoid Adults } \\
\cline { 2 - 3 } & $\begin{array}{c}\text { No. } \\
\text { Tested }\end{array}$ & $\begin{array}{c}\text { No. } \\
\text { Pos. }\end{array}$ & $\begin{array}{c}\text { Tuberculin } \\
\text { Index }\end{array}$ & $\begin{array}{c}\text { No. } \\
\text { Tested }\end{array}$ & $\begin{array}{c}\text { No. } \\
\text { Pos. }\end{array}$ & $\begin{array}{c}\text { Tuberculin } \\
\text { Index }\end{array}$ \\
\cline { 2 - 3 } Mantembu & 168 & 68 & 40.5 & 37 & 10 & 27.0 \\
Mariadei & 162 & 121 & 74.5 & 9 & 5 & 55.0 \\
Wandamen & 933 & 724 & 78.1 & 67 & 46 & 68.8 \\
Mooi & 243 & 113 & 46.5 & 37 & 9 & 24.3 \\
\hline Total & 1,506 & 1,026 & 68.1 & 150 & 70 & 43.7 \\
\hline
\end{tabular}

\section{Discussion}

CHAUSSINAND $^{3}$ has put forward the hypothesis that an increase of tuberculosis is followed by a decrease in leprosy. Leprosy indices are highest in countries where the tuberculosis morbidity has not yet reached a high peak. Most articles speak about the leprosy index only. A relation between the tuberculosis index and the type of leprosy has not of ten been mentioned.

It is difficult to draw conclusions from these first surveys in New Guinea about the influence of tuberculosis on the incidence of lepromatous and borderline leprosy, since in many areas leprosy has been introduced recently, and probably also tuberculosis is a rather new disease, even in some coastal areas. It is not possible to trace the exact date of introduction of tuberculosis in these areas. A long follow-up period in some areas will be needed to evaluate the influence of tuberculosis on lepromatous leprosy.

The most important conclusion that may be drawn from this study is that a high relative susceptibility for tuberculoid leprosy goes along with a low tuberculosis index. The lower leprosy index in tuberculosis-rich areas at the coast may be explained by the hypothesis that previous tuberculosis contact prevents the development of a high percentage of tuberculoid lesions.

The development of the leprosy epidemic at Mantembu and other places, although less severe, does not differ essentially from the well 
known epidemic at Nauru. There, the first "nodular" patient was seen in 1920. In 1923, 139 leprosy patients were found. After a history of 20 years a leprosy index of 350 per thousand was reached. From the isolated patients $68 \%$ were of the "macular" type. In 1929 BRAY $^{4}$ reported that $90 \%$ of the cases were tuberculoid, mutilation being uncommon (minor tuberculoid variety), that in almost every family cases of leprosy were found, that the sex differentiation was negligible, and that $58 \%$ of the patients were older than 20 years at the onset of first symptoms $\left(\mathrm{WADE}^{5}\right)$. Tuberculosis was rare then in Nauru.

DAVEY ${ }^{6}$ described the leprosy situation in tribes living "in conditions of relative isolation" in Nigeria. The leprosy index was high ( 121 per thousand), the type rate low $(8.8 \%$ ), and in $57 \%$ of the cases a single or only few tuberculoid macules were found. Tuberculosis was a rare disease in those areas. It was impossible to explain the epidemiology by the idea of intensive prolonged contact with lepromatous patients only.

Although probably more factors are involved, the following hypothesis explains a great deal of the findings. A newborn child has no effective immunity against leprosy (young babies do not react to lepromin).

How susceptible young children are can be learnt from the study of LARA $^{7}$ at Culion. From the children born in the leprosarium, living in contact with their sick parents, $25 \%$ showed symptoms of leprosy before the age of five. However, in $85 \%$ of the cases spontaneous arrest of the disease was seen, and a long follow-up revealed that these children had permanent positive lepromin reaction. Probably these children were already potentially immune at birth, but the potential relative immunity had to be transformed into an effective immunity by contact with $M$. leprae.

The same process we may see in older patients with tuberculoid leprosy. At the onset the patient has no effective immunity against $M$. leprae. The leprosy bacillus has the opportunity to multiply. Visible lesions appear. In the meantime immunity develops, at first at the place where bacilli have multiplied, i.e. the central part of the tuberculoid macule. Later on the immunity is sufficiently advanced to stop further spread of the lesions and at the end the immunity may be strong enough to allow the patient to come in contact with lepromatous patients without danger of developing further symptoms of leprosy.

In young children the effective immunity is nil. However, most children possess a hereditary potential (relative) immunity, of a variable degree: Several factors may have influence on the transformation of this potential immunity into an effective immunity. The influence of non-pathogenic acid-fast bacilli is weak. $M$. leprae and M. tuberculosis are more effective. If the potential immunity is very 
high, contact with acid-fast bacilli will produce a sufficient immunity to kill the bacilli in a very short time. If the potential immunity is not so high the bacilli will have time to multiply and visible lesions will appear. If such a child should come in contact with leprosy bacilli before he has contact with $M$. tuberculosis, leprosy symptoms of the self-healing tuberculoid type may appear. However, if he had tuberculosis contact before leprosy contact his potential immunity would already have been transformed into an effective immunity and no symptoms of leprosy would appear. A small number of children might have only minimal potential immunity or none at all, and in these children the disease would develop into a borderline or lepromatous type. Tuberculosis contact would not change this unfavourable condition.

In a community with much tuberculosis the number of adults who have reached the stage of sufficient effective immunity against $M$. leprae is much higher than the number of children. If leprosy is introduced in such a community only adults without sufficient potential immunity will contract a malignant type of leprosy and a minority with more potential immunity but who have not been in contact with $M$. tuberculosis will show symptoms of tuberculoid leprosy. In children the incidence of tuberculoid leprosy will be higher.

In a community with a few cases of tuberculosis the percentage of potential immune adults who have not reached the stage of effective immunity is almost as high as among children and many adults will show tuberculoid macules after introduction of leprosy. This seems to be the situation in the areas described in this article and at Nauru, West and Central Africa, etc.

From lepromin and tuberculin surveys ${ }^{8}$ we conclude that some individuals do not show a positive lepromin reaction, even after contact with different types of acid-fast bacilli, $M$. tuberculosis included. In other individuals the lepromin reaction remains so weak that some local resistance against $M$. leprae is possible, but this low immunity is insufficient to stop the disease (borderline leprosy). Probably these individuals lack a hereditary factor which is essential to enable the body to destroy the bacillus completely. If this hypothesis is right, there is no reason to expect that tuberculosis contact will change this condition and also nothing is to be expected from BCG vaccination. Only in individuals with a sufficiently high potential immunity will tuberculosis contact or BCG vaccination prevent the development of tuberculoid lesions.

It is still possible that BCG vaccination has some effect in individuals with a weak potential immunity. The possibility remains that a weak effective immunity is sufficient to destroy a small number of bacilli. If such a person has no repeated contact with lepromatous patients, he may be able to destroy incidental invasion of small 
numbers of bacilli and remain free of leprosy. Furthermore, under conditions as described in this article, the effect of contact with tuberculosis and of BCG vaccination may influence the incidence of lepromatous and borderline leprosy indirectly.

In a susceptible environment, tuberculoid cases which are temporarily positive can act as a source of infection. When the incidence of tuberculoid leprosy is reduced by $\mathrm{BCG}$ vaccination, the chance that susceptible individuals come into contact with leprosy bacilli is also reduced, which may result in a decrease of new malignant cases of leprosy too.

In several of the areas described in this article we have noticed a spontaneous decrease in the evidence of new cases of tuberculoid leprosy, after the epidemic had reached a high peak. This may be explained by the fact that in every community there is a limited number of susceptible individuals. If the disease spreads fast, most individuals will soon have been in contact with leprosy. Those with a high potential immunity have shown nothing but a conversion of the Mitsuda reaction into positive; those with a lower potential immunity have shown tuberculoid leprosy; the few people without potential immunity show or will show lepromatous or borderline leprosy. The susceptible reservoir is soon exhausted and the incidence will decrease. Only some cases with a longer incubation period appear together with some cases in people who have escaped contact with the bacillus before. Only among the newborn children new susceptible individuals are found and the child index will rise. A second source of susceptible individuals is found in people who come into the community from the outside, by marriage etc. (BoENJAMIN $\left.{ }^{8}\right)$. The leprosy index will decrease and the type index will increase.

Of course, factors such as density of the population, hygiene, customs, segregation of patients, treatment, etc., play some role, different in each situation. However, these factors are probably of secondary importance. One has to consider the possibility that the decrease in the incidence of new cases at Nauru and in Africa was only partly the result of the anti-leprosy campaign and mainly the natural course of an epidemic in a susceptible environment.

In New Guinea this was certainly true, since a significant decrease was noticed before effective anti-leprosy measures had been taken. Measures, such as were taken at Nauru during the epidemic, in other countries failed to reduce the incidence of leprosy appreciably.

The question remains why the susceptible stock seems to be so different in many countries. This may be partly the effect of natural selection. From the genealogical point of view borderline and lepromatous patients are of major importance. In underdeveloped countries, but also elsewhere, before the sulphone period lepromatous patients had less opportunity of marrying than healthy people, especially when the disease started before adolescence and 
was followed by mutilation or other severe symptoms. The average lifetime of married lepromatous patients was shorter than of healthy people. Advanced lepromatous leprosy may produce sterility in the male. In the poor condition of general health, the patients were less able to take good care of their children, which resulted in a higher death rate. The chance of abortion was increased in the female patient. These factors together result in a diminished offspring compared with healthy people. Thus after several generations the susceptible stock in a community may decrease. Although nowadays early treatment of cases, better social care, and a changed attitude towards the disease in most civilised countries have reduced the influence of these factors to a minimum, they are recent history and still operative in several countries where leprosy is endemic.

These conceptions have important practical consequences. It is not justifiable to base control measures on general statements such as the low infectivity of the bacillus, the low infectivity for adults, etc. It is not the more or less infectivity of the bacillus which counts, but the susceptibility of the community. Every anti-leprosy campaign must be based upon intensive and extensive local surveys, and study of the trends of leprosy in these areas: In some countries it may be quite unnecessary to insist on any segregation measures at all. In other countries early dispensary treatment, mobile treatment teams, leprosy villages, or some kind of relative segregation will be sufficient to produce a gradual decrease in the leprosy incidence. For such countries, therapy with a faster activity than sulphones may solve the leprosy problem in a short period.

However, susceptible communities give the choice of waiting till tuberculosis is widespread and the susceptible stock is reduced by natural means, or radical measures, including repeated intensive surveys, early voluntary segregation of all bacterially positive cases and BCG vaccination of all tuberculin-negative individuals, It is doubtful whether half-hearted measures which are relatively expensive are worth the cost. Besides, much social harm is done, without the balance of obvious benefit to the community. If segregation of the majority of patients living in contact with susceptible individuals is not possible for one reason or another in a very early stage of the disease and on a voluntary basis, it seems wise not to spend too much money on segregation of a minority of patients in a rather late stage of the disease, but to use the available funds for early case-finding, treatment, education, and $\mathrm{BCG}$ vaccination.

\section{Summary}

The history of leprosy in Netherlands New Guinea is described. In many parts of the country leprosy has been introduced only recently. The disease spread from the coast to the interior, and was studied from its introduction into the community in several tribes. 
It was found that in tribes which. have lived in relative isolation until recently leprosy follows a pattern which does not differ essentially from that described from Nauru, New Caledonia, and parts of Central and West Africa. This epidemiology has the following characteristics:

(a) The disease spreads fast and the leprosy index becomes very high.

(b) Most cases are of a mild minor tuberculoid type.

(c) Cases are found in the majority of the houses in the village.

(d) Adults are almost as susceptible as children.

(e) Most patients did not have contact with lepromatous cases.

This epidemiological picture was found only in areas with a low tuberculin index. The differences in tuberculin index between these tribes and coastal tribes with a more common epidemiology were highly significant statistically, likewise in the tuberculin index of tuberculoid patients compared with healthy people from the same age group in the same area. The epidemiology is explained by the hypothesis that in people who possess a potential immunity against leprosy contact with tuberculosis produces an effective immunity, which prevents the development of tuberculoid leprosy symptoms in many people. It is improbable that tuberculosis contact gives any protection in people who do not have a sufficient potential immunity.

However, as some tuberculoid patients may act temporarily as a source of infection, it is possible that the reduction of the incidence of tuberculoid cases by tuberculosis contact or BCG vaccination may have an indirect effect on the incidence of lepromatous leprosy too. Therefore, although BCG vaccination does not guarantee individual protection against leprosy, it seems to be of definite value, especially in highly susceptible communities.

\section{References}

1. Leiker, D. L. and Sloan, N. R. (1954) "Leprosy in Netherlands New Guinea" Int. Journ. Lep., 22, 4, 431.

2. Wissmuller, G., Chief of Division of Tuberculosis Control, Netherlands New Guinea. Personal Communication:

3. Chaussinand, R. (1944), Rev. Med. France. E.-O., 22, 667. Int. Journ. Lep. (1948), 16, 431.

4. Bray, G., (1930) "The Story of Leprosy at Nauru". Proc. Royal Soc. of Med., Section Trop. Dis., 23, 1370.

5. Wade, H. W., Ledowsky, V., (1952) "The Leprosy Epidemic at Nauru". Int. Journ. Lep., 20, $1,1$.

6. Davey, T. F. (1957) Int. Journ. Lep., 25, 4, 329.

7. LARA, C. B., (1948) "Leprosy in Infancy and Childhood". Bull. Bureau of Health, Philippines 24, 2, 61.

8. Leiker, D. L., "Een lepromine-tuberculine Survey ine de Wandamenbaai". (1958) Med. D.V.G. Ned. N. Guinea, 5, 3, 54.

9. Raden Boenjamin. "Épidemiologisch onderzoek naar de betekenis van de duur en de aard van het contact met lepralijders." (1949) Thesis, Batavia. 